\title{
The "In-Factor": Signature Traits Of Innovation's Leaders
}

\author{
Susan Eisner, Anisfield School of Business at Ramapo College of New Jersey, USA
}

\begin{abstract}
This paper was inspired by the 2013 film Jobs, the docu-drama about Apple founder and longtime CEO Steve Jobs whose leadership style in some ways so contradicted contemporary leadership prototypes that he is sometimes said to depict the "anti-leader." That film triggered this question: Are there attributes that, regardless of behavioral bent, those who lead innovation share? Through a review of academic and practitioner literature an "IN-factor" such leaders share emerges: The intention and insistence to be trailblazers. Though leaders of innovation travel different paths and are not all alike, though some are mavericks and others break through existing challenges, though some are founders and others are successors, though some are college educated and others are not, these "Imagineers" share ten signature traits which this paper establishes should it be helpful to contemporary leadership education, development, and training.
\end{abstract}

Keywords: Leadership Education and Development; Leadership Style; Leaders of Innovation; Contemporary Leadership

\section{INTRODUCTION}

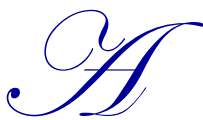

ccording to the Merriam-Webster Dictionary, innovation is "the act or process of introducing new ideas, devices, or methods;" its first known use is noted in the $15^{\text {th }}$ century ${ }^{\mathrm{i}}$. Now, a Google search for the keyword innovation produces some 136,000,000 results, for importance of innovation in business produces $111,000,000$ results, for innovation management produces $358,000,000$ results, and for innovation leadership produces $361,000,000$ results. The concept of innovation, as an aspect of business in particular and as a process to be led, appears to be an enduring one with widespread roots foundational to business activity.

Contemporary business headlines report attendant deliverables. Stories of college dropouts including Apple's Steve Jobs, Dell's Michael Dell, Dream Works SKG's David Geffen, Facebook's Mark Zuckerberg, Microsoft's Bill Gates, Ralph Lauren Corp.'s Ralph Lauren, Tumblr's David Karp (high school dropout), and Twitter's Evan Williams who became super wealthy through start-ups they founded and grew are an iconic part of contemporary culture. Studying such modern-day titanic innovators is an integral part of business education today, and enhances their impact as role models for those preparing to manage and lead.

Headlines also spotlight college-educated executives whose capacity to envision or re-imagine has been seismic. Undergraduate colleges they graduated from are wide-ranging and include Amazon.com's founder Jeff Bezos, Princeton; Apple's Tim Cook, Auburn; Disney's Robert Iger, Ithaca; Google's co-founder Larry Page, University of Michigan; Facebook's Sheryl Sandberg, Harvard; Harpo's founder Oprah Winfrey, Tennessee State University; J.C. Penney's former CEO Ronald Johnson, Stanford; Southwest Airline's co-founder Herb Kelleher, Wesleyan; Starbuck's Howard Schultz, Northern Michigan University; The Container Store's co-founder Kip Tendell, University of Texas at Austin; The Weinstein Company's co-founder Harvey Weinstein, SUNY Buffalo; Xerox's Ursula Burns, Polytechnic Institute of New York; Yahoo's former CEO Carol Bartz, University of WisconsinMadison; Yahoo's Marissa Mayer, Stanford; and Zappo's Tony Hsieh, Harvard.

Concurrently, the mostly Generation Y (Gen Y) student ${ }^{\mathrm{ii}}$ is increasingly drawn toward starting a business rather than seeking to work for others, and some 54\% of Gen Y report having started their own business or wanting to ${ }^{\text {iii }}$. Gen Y entrepreneurial desire does not appear to be a faraway dream. Gen Y career and workplace expert Dan Schwabel 
cites $46 \%$ of Gen $Y$ wanting to start their own businesses within the next five years. Moreover, he cites $90 \%$ of Gen $\mathrm{Y}$ seeing entrepreneurship as a state of mind rather than ownership of one's business ${ }^{\text {iv }}$.

Those conducting leadership education, development, and training programs for this incoming generation to the leadership pipeline may confront a cohort group whose leadership prototype is somewhat romanticized by tales of mega-successful iconic start-ups. Examples of challenges many who eventually succeeded confronted along the may not be widely known, and the overarching successes of many innovative executives who reached that rank through years of traditional training and experience may be similarly overshadowed.

As a result, it may be helpful for those charged with stocking the leadership pipeline, and for those considering whether or not to join that pipeline, to have established that the innovative attribute these contemporary leaders share is the intention and insistence to be trailblazers, whether as mavericks or whether as those who break through existing challenges. That IN-Factor may or may be linked to having conceived a breakthrough product or service, and may be operationalized in various ways.

\section{PURPOSE AND METHOD}

This paper was inspired by the 2013 film Jobs, directed by Joshua Michael Stern. Literature has long chronicled that Apple founder and longtime CEO Steve Jobs led his company to the pinnacle it reached by "behaving more like an old-fashioned industrial titan than a different-thinking business of the future ... (that is) in ways opposite to the standard touchy-feely philosophies of Silicon Valley" (Kahney, 2008). Those of us who teach business leadership sometimes cite Jobs as an illustration of the "anti-leader," so contrary to the contemporary leadership prototype is the typical depiction of him. In seeing that film, though, a totality of attributes that Jobs possessed, applied, and was sparked by crystallized and triggered this question: Are there attributes that, regardless of behavioral bent, those who lead innovation share?

This study was conceived within that context, and seeks to contribute to a timely and important aspect of leadership education, development, and training by clarifying that innovation's leaders need not all travel the same path and do not all behave alike, founding a start-up is not a necessary or sufficient attribute for innovative leadership success, and learning is associated with innovative leadership success. The specific focus of this study is to identify signature traits that leaders of innovation share. Collectively, those attributes will be labeled as and describe the "IN-Factor" of contemporary leadership of innovation.

The paper continues the groundwork that was laid in two recent papers by its author: "Reflections on Leadership" and "Leadership and Gender." Both of these papers found that contemporary executives tend to focus on both people/relationship and task/result aspects of work, exhibit an authentic orientation, and apply a transformational/ change agent approach.

From that foundation, Andrew Dubrin's comprehensive coverage of creativity, innovation, and leadership in his textbook Leadership: Research Findings, Practice, and Skills ( $7^{\text {th }}$ edition) was examined specifically for this paper to provide additional grounding from the extant literature on personal characteristics and leadership practices that tend to enhance innovation ${ }^{\text {vi }}$. Current academic and practitioner literature was then reviewed to identify signature traits of contemporary leaders of innovation such as those listed above reflecting the range of those who founded, partnered, transformed, successfully led innovation, and/or did not succeed. Finally, twelve representative leaders were researched to study specific examples of innovation's leaders. The resulting literature base encompasses both primary source first person reflections of the leaders, and secondary source findings regarding the leaders' relevant traits.

\section{LITERATURE REVIEW}

A widely cited Background Note prepared by Harvard Business School professor Teresa Amabile for her $2^{\text {nd }}$ year MBA students defines innovation as "the successful implementation of creative ideas within an organization" and creativity as "the production of novel and useful ideas in any domain" (Amabile, 1996). Chapter 11 of Dubrin's Leadership: Research Findings, Practice, and Skills textbook $\left(7^{\text {th }}\right.$ edition, 2013) identifies four personal 
characteristics that, when possessed, may increase the likelihood of a leader's creativity, which is thus the foundation of innovation. The first of these characteristics is knowledge: the breadth and depth of background information a leader has. The second characteristic is cognition: the leader's ability to both generate original ideas and also to refine and choose among them, to see opportunities others may not, and to have a curious mindset. The third characteristic is personality: the leader's comfort with working in the relative isolation from which strong ideas often emerge, tendency to seek intellectual thrills and find uncertainty/ambiguity enjoyable, and likelihood of being a nonconformist maverick in need of self approval more than other approval. The final characteristic Dubrin reports to be predictive of a leader's creativity is "passion for the task and the experience of flow:" the leader is enthralled with what $\mathrm{s} / \mathrm{he}$ is doing, is totally absorbed in and by it, and is intensely and intrinsically driven to do it.

Dubrin's summary of existing research also reports that the above characteristics may increase likelihood of a leader's creativity, but environmental factors impact whether and to what extent that creativity is triggered in the leader. Central to that is an organizational climate which promotes and supports innovation and an organizational culture that operationalizes innovation through leadership practices that activate, acknowledge, and utilize it. Those leadership practices include leading transformationally, continually pursuing innovation, taking risks and encouraging others to do so, emphasizing collaboration among workers and among teams, acquiring innovative companies, integrating development and production, recognizing hidden opportunities when ideas flop, avoiding innovation for its own sake, and practicing "loose-tight" leadership which encourages new ideas but chooses among and uses the best amongst them. Further, research Dubrin summarizes suggests that leaders who enhance innovation hire and unleash creative people, challenge them intellectually and through appropriate time pressure, allow them to choose their methods, supply them with sufficient resources, form diverse work groups, encourage open thinking and idea exchange, recognize and reward creativity, and have favorable exchanges with creative workers (Dubrin, 2013).

A comprehensive review of Harvard Business publications finds many reporting on attributes of $21^{\text {st }}$ century's leaders of innovation. Daniel Goleman, whose classic description of "emotional intelligence" in 1995 identified selfawareness, self-regulation, motivation, empathy, and social skill to be among essential leadership qualities (Goleman, 2004), in 2013 reported that those seeking to lead others toward innovation and strategy must first be able to be "focused leaders" in touch with and in charge of their own attention. That focus should be applied inwardly to one's self, outwardly to others, and externally to the wider world. This tri-part awareness allows the leader to think freely and well, unencumbered by becoming distracted or being blindsighted (Goleman, 2013).

A two-day colloquium on leading innovation convened by Harvard Business School professors attended by key scholars and executives concluded that creativity cannot be managed, but it can be managed for. Their proscriptions for leaders who seek to manage for creativity successfully are to promote and champion ideas rather than to be their source, ask questions that inspire and stimulate the imagination of all workers, utilize diverse perspectives and ease creative interaction amongst them, and minimize bureaucratic obstacles. Weak ideas should not be pursued, and learning from failure should be facilitated (Amabile and Khaire, 2008).

Menkes' 2011 study of successful $21^{\text {st }}$ century leaders reports that the change and uncertainty in which modern organizations tend to function require leaders who trigger a drive to achieve in those they lead. Leaders who are able to accomplish this do three things. They "make the real world palpable," advance belief in the organization's core mission, and promote a sense of ownership for one's performance (Menkes, 2011).

Sprier et al. specifically examined the potential deterrent effect on others of an achievement-driven leader who overly focuses on task and goal performance of others and uses an autocratic style in doing so. They report that leaders who can energize and trigger high performance in others are adaptable stylistically, coach, supply vision, and seek buy-in and commitment from others rather than seek to lead by command and control (Spreier et al., 2006).

Alternatively, that same year Kramer examined how some tough, "in your face" leaders seem to succeed. He clarifies that these "great intimidators" are not classic bullies since they are fueled positively by vision rather than by negative intent to harm. He describes such leaders as having "political intelligence" with which they identify and use others' vulnerabilities to trigger action, rather than as utilitizing "social intelligence" to identify and use others' strengths to trigger action (Kramer, 2006). When circumstances require transformation but a leader confronts solid 
resistance, the intimidating leader may be a more effective innovator than one who leads empathetically and positively. Some of those Kramer interviewed reported doing their best work when led by intimidating leaders, and some described having been fascinated by them (Weisman, 2006).

Macoby studied the "narcissistic leader" who also marches on apparently immune to input or feedback. He focused on emergence in the dot-com era of these "rock star" outsized visionaries who are dare devils with passion and courage to match, but appear to be deaf-eared to others' ideas. His proscription for such a leader is to pair with a more pragmatic partner who is operationally-focused and rooted (Maccoby. 2004).

Leadership expert Warren Bennis examined what distinguishes those who seem to just know how to inspire others. Such leaders seem to have experienced "intense, often traumatic" formative events that shaped them going forward. Having had to face what they were and what mattered to them, they emerged and moved forward confidently and purposefully (Bennis and Thomas, 2002).

Other academic research is consistent with these findings. Bell and Patterson, for instance, report that contemporary times require "boldness, innovation, and bringing out the best." So today's successful leaders are authentic, egalitarian, enthusiastic, trust-worthy, humble, other-oriented "champions." Such leaders tend to forge a compelling, relevant, and consistent vision and ground all they do on it. They are visible, present, and inclusive, and partner with those they lead. They lead as much but as little as is needed; they inform, resource, support, and do not interfere. They base relationships on vision not power, and make it safe to make mistakes from which to learn. They give and keep their word all the while fostering responsible risk-taking. Finally, they celebrate and convey gratitude to enhance compassion, and inject lightness into the culture to reduce tension (Bell and Patterson, 2013)

Alvarez, Svejenova, and Vives suggest, like Macoby, that sometimes optimal contemporary leadership occurs in leadership "pairs" rather than singularly. Having studied more than 100 companies they found that shared leadership can be beneficial when collaboration is between those who are compatible, mutually committed, possessed with attributes each other lacks, clear about collective and sole responsibility including communication, and willing to let the relationship develop over time and adapt to changing conditions (Alvarez et al., 2007).

Practitioner literature is equally full and consistent. In 2011, for example, Adam Bryant reported five success qualities that today's top leaders have in a book ${ }^{\text {vii }}$ based on interviews with more than 70 such leaders conducted for his "Corner Office" column of The New York Times Business section. Bryant found these leaders to share "passionate curiosity," "battle-hardened confidence," "team smarts," "a simple mind-set," and "fearlessness." That is, such leaders are palatably energized. They wonder about people, processes, opportunities, challenges, and rebounding. They tell stories and are interested in others' stories. They ask big picture and stretch questions, as they are in a continual learning mode and ever seek best practices. They not only handle adversity but value it, having experienced and overcome it, and are fueled by a strong work ethic and sense of responsibility grounded on that. They seek others who are comfortable with failure and who take ownership for it, reflecting the internal locus of control these leaders possess. Additionally, such leaders can detect the combination of people a team needs, how they will interact, and how to align them toward a shared goal. These leaders are focused and want others to also know, clarify, and get to their points. Finally such leaders are comfortable with discomfort; they embrace changes through reasoned risk-taking as a route to unlocking opportunity (Bryant, 2011).

A 2007 book by George and Sims echoes Bennis and Thomas' earlier finding of the strong role which formative life experience and crises tend to have in shaping the "burning sense of mission" that appear deeply ingrained in innovation's leaders. The result is a "deep desire to serve a greater goal beyond simply making money." These leaders possess and display a clear authentic set of values, a "true north," that those who work with them recognize and respect (Holstein, 2007). Table 1, below, provides an overall summary of characteristics associated with contemporary leaders of innovation detailed in the above literature review: 
Table 1. Summary - Literature Review

\begin{tabular}{l|l}
\hline \multicolumn{1}{c|}{ SOURCE } & \multicolumn{1}{c}{ Characteristics } \\
\hline Dubrin & $\begin{array}{l}\text { Knowledge, cognition, personality enjoying uncertainty, non-conformist maverick seeking self- } \\
\text { approval, passion for task and experience of flow }\end{array}$ \\
\hline $\begin{array}{l}\text { Harvard Business } \\
\text { Publications }\end{array}$ & $\begin{array}{l}\text { Tri-part focus, trigger drive to achieve, manage for creativity, learn from failure, adapt stylistically, } \\
\text { coach, supply vision, seek buy-in and commitment, fueled by vision, politically/emotionally/socially } \\
\text { intelligent, dare devil with passion and courage, partner with operational pragmatist, experienced } \\
\text { intense/traumatic formative event, confident, purposeful }\end{array}$ \\
\hline $\begin{array}{l}\text { Other Academic } \\
\text { Literature }\end{array}$ & $\begin{array}{l}\text { Bold, bring out best in others, authentic, egalitarian, enthusiastic, trust-worthy, humble, other-oriented, } \\
\text { champion ideas, visible and present, base relationships on vision not power, make it safe to make } \\
\text { mistakes from which to learn, foster responsible risk-taking, inject lightness, pair and evolve }\end{array}$ \\
\hline Bryant & Passionate curiosity, battle-hardened confidence, team smarts, simple mind-set, fearlessness \\
\hline George and Sims & Burning sense of mission, greater goal beyond money, true north value set \\
\hline
\end{tabular}

Academic and practitioner literature, then, provide an overview of characteristics and behaviors that tend to be associated with leaders of innovation. To determine how these attributes are actually manifest in practice, and to identify specific signature traits that such leaders share, twelve individual leadership examples were then examined. As the examples show these leaders to be holistic, tending to combine right brain creativity with left brain logical strength, and tending to combine reliance on intuition with consideration of data, they are collectively labeled below as "Imagineers." Six of the twelve are among those CNNMoney included in its 2012 ranking of "The Twelve Greatest Entrepreneurs of Our Time" "viii: Steve Jobs \#1, Jeff Bezos \#4, Larry Page (and Sergey Brin) \#5, Howard Schultz \#6, Mark Zuckerberg \#7, and Herb Kelleher \#9. Three of the twelve are among the four CEO's Forbes included in its list of "2012 CEO All-Stars": Tim Cook, Most Successful CEO Successor; Jeff Bezos, Best Execution by a CEO; and Howard Schultz, The Most Civic-Spirited CEO. Two others are among the four Forbes included in its list of "Aspiring Stars of 2013": Marissa Mayer and Ron Johnson (Battley, 2012).

\section{IMAGINEERS}

\section{Herb Kelleher, Co-Founder, Chairman Emeritus, and Former CEO of Southwest Airlines}

Southwest Airlines' website lists the multitude of awards and honors earned by Herb Kelleher and the breakout results of his leadership. Those include Southwest Airlines being the only airline to be named by Fortune as one of ten "World's Most Admired Companies"

Colleen Barrett, who succeeded Southwest Airlines Co-Founder Herb Kelleher as President upon his retirement having worked closely with and been mentored by him, describes Kelleher as having "preached about being quick to take advantage of opportunities because they only come once - and they're fleeting. If you don't take them, someone else will." Barrett describes Kelleher's innovations as Southwest's hallmark customer service, treating all employees as family members, making their work environment enjoyable, and having that circle back to exceptional customer experience (Barrett, 2011).

Kelleher, a lawyer, credits Southwest's financial success to that culture, and describes that culture to be what he worked on most. He is clear in connecting the two and the importance of doing so to him, explaining it - and illuminating his clear vision - this way: "Keeping costs low and spirits high are the two things I focus on." Kelleher further describes the importance of attitude and the specific value of humility, modesty, selflessness, and altruism. Reflecting that other-centered, "hire for attitude" culture, be yourself - be free, "spirit de corps," have fun, and dogood vision, Kelleher has been labeled "extrovert-in-chief." The rationale? Kelleher describes letting people be who they are, which includes telling jokes if they want to, as a route to unleashing their creative energy and imagination (Air Herb's Secret Weapon, 1999).

\footnotetext{
${ }^{1}$ The term "Imagineer" was first coined by Alcoa in the 1940s to express the combination of imagination and engineering, used by Union Carbide in 1957, and copyrighted by Disney in 1967 (https://en.wikipedia.org/wiki/Walt_Disney_Imagineering).
} 


\section{Howard Schultz, Chairman, President, and CEO of Starbucks}

Starbucks Chairman, President, and CEO Howard Schultz like Kelleher came from an impoverished background. Also like Kelleher, Schultz has been described as authentically other-oriented and an able story-teller. Schultz's depiction as "a natural-born salesman" is reported to stem from his having sold word processors door to door (Whitworth, 2011).

Schultz's leadership style is said to combine toughness, drive, total commitment, and focus with the softness to cry publically. He describes his work ethic, in which he sleeps at most four hours per night, this way: "You've got to be all in." To Schultz the deliverable is generating profits while doing good, especially for employees, whom are called "partners" and who greet Schultz by his first name (Whitworth, 2011).

Schultz is also reflective and candid. When assessing the low his company reached that prompted his return in 2008 after eight years away to its lead, after which it rebounded, Schultz describes the "hubris" he had had as responsible for the company's downturn. Those close to Schultz report the experience to have changed him. Though still described as "fanatical" about Starbucks, he is since also described as "humble." Schultz describes that leadership attribute this way: "What leadership means is the courage it takes to talk about things that in the past, perhaps we wouldn't have, because I'm not right all the time" (Miller, 2011b).

Schultz links his leadership style to having grown up insecure about being "a poor kid," developing sensitivity toward those from similar backgrounds who are not respected and then develop low self-esteem, and subsequently determining to demonstrate that he is not "in some ivory tower." Schultz describes the result this way: "I think the leadership style I have is that I've never put myself above anyone else, and I've never asked more of anyone that I was willing to do myself." He considers his strengths to include ability to read people, to appreciate and know how to build a functional team that is mission-centered and so coalesces through essential "creative tension," to be selfcritical, and to be wholeheartedly engaged in what he is doing. Schultz also explains the importance of being surrounding by people with whom there can be mutual trust, open and honest dialog, and the display of vulnerability that he says is the basis of mutual trust (Bryant, 2010).

\section{Steve Jobs, Founder and Former CEO of Apple}

Apple also experienced its long-term CEO Steve Jobs' return after years away (1985-1996) to restore a declining company. Though Schultz had left Starbucks voluntarily and Jobs had not wanted to leave Apple, both successfully returned their companies to robust positions after resuming the lead. In 2009, Fortune magazine declared "The Decade of Steve" in an article subtitled "How Apple's Imperious, Brilliant CEO Transformed American Business." That article notes Jobs as uniquely being the key and transformative player in four different industries: music, movies, mobile telephones, and computing. It further reports Jobs to be an international celebrity who is "a showman, a born salesman, a magician who creates a famed reality-distortion field, a tyrannical perfectionist." It also describes Jobs as "often unpleasant" and "all about business," combining big-picture visioning with microfocus as he immersed himself, and relying on his own intuition rather than market data to imagine and create products customers would want. Job's tight control extended to company messaging and turned his combined "penchant for secrecy and surprise and his proven brilliance" into legendary leadership style and corporate competitive advantage to such an extent that Google co-founders Larry Page and Sergey Brin reported Jobs to be their hero (Lashinsky, 2009).

Notes for a 2010 international academic case on Steve Jobs and Apple identified several attributes as contributing to his success: passion, intelligence and confidence, resourcefulness, visionary and opportunistic nature, drive and work ethic, willingness to take risks, charisma and persuasiveness, and strong need to achieve (Finkle and Mallin, 2010). Jobs said he thought of himself as a leader, not as a manager, and that leadership is centered on "choosing the best people possible, encouraging them and creating an environment in which they could do great work" (Lohr, 2011).

Job's style, like Schultz's, is seen to have evolved over time. After Job's 1996 return to Apple he is reported to have interfered less, been less abrasive, listened more, and trusted team members more. At the same time, he is said to 
have retained his defining mixture of vision, creativity, and decisiveness (Lohr, 2011). That combination is offered as explanation for the loyalty of Jobs' employees, despite high standards by which he judged every detail and tirades he might direct at employees. Kahney explained it in 2008 this way: "Jobs's employees remain devoted. That's because his autocracy is balanced by his famous charisma - he can make the task of designing a power supply feel like a mission from God ... (and) He was almost always right." A Harvard Business Review article further describes Jobs' impatience as part of the perfectionism that reflected the passion and intensity which he brought to all aspects of his life and work (Isaacson, 2012).

\section{Tim Cook, CEO of Apple}

Upon Steve Jobs' death his chosen successor Tim Cook, whom Jobs recruited to Apple in 1998 and whom he had chosen to lead it during his eventually fatal illness, became Apple's CEO. There, many stylistic similarities between these two men might appear to end. Cook, an engineer, is trained to be analytical and make decisions objectively, whereas Jobs is reported to have relied more on instinct and emotion. Moreover, Cook is described as soft-spoken, while Jobs could be brittle. But Cook shares Jobs' passion for Apple, and describes it as a place which gave him opportunity to perform "truly meaningful work" (Kopytoff and Streitfeld, 2011).

Formerly Apple's COO, Cook also shares Jobs' devotion to quality, having led and transformed the company's operations in a way that is said to have become a model for supply chain management. Cook, also like Jobs, is a workaholic with a brilliant mind focused on execution. His intensity appears to be more muted than Jobs' was, though. Cook is also said to be calmer and to make his mark more quietly than Jobs did (Chmielewski and Guynn, 2009). A longtime Apple analyst has described Cook as "the kinder, gentler Apple." One manifestation of this is Cook's sense of the company's social responsibility, particularly its "responsibility to create jobs" and "to give back to the communities." Neither of these was among Jobs' stated objectives (O'Brien, 2012).

\section{Ron Johnson, Former CEO of J.C. Penney}

Traits of a leader that succeeded at one company do not necessarily predict success at another, even when the leader honed those traits at Apple. Ron Johnson, credited with the trendsetter Apple Stores and success at Target prior to that, was hired by J.C. Penney as CEO in 2011. He was fired 17 months later. Among lessons here are guidelines for the impact of a leader's use of humor, and its impact on transformation. Humor that reduces stress, unleashes creativity, and humanizes like Kelleher and Schultz espouse can be an asset. But Johnson is said to have ridiculed and sarcastically put down the existing marketing strategy and team he found upon arrival at J.C. Penney, as well as the traditional J.C. Penney customers and their taste. In doing so, Johnson signaled that he envisioned J.C. Penney becoming a very different store (Clifford, 2013).

That intent was further clarified as Johnson replaced most of J.C. Penney's existing executives and put in their stead his own team from Apple and Abercrombie \& Fitch, two stores very different from the J.C. Penney he found. Neither Johnson nor the new executives relocated to Texas, where J.C. Penney is headquartered (Clifford, 2013).

J.C. Penney employees described Johnson as "a hard worker, decisive, and responsive to even late-night e-mails." But he is said to have wanted the same compliance with his ideas as CEO that Jobs had commanded at Apple. Johnson is also reported to have resisted feedback that questioned his vision and, like Jobs, to have believed in his own taste and that he knew what the customers wanted regardless of data. Only when sales significantly trended downward, after his strategy was implemented, did Johnson begin to ask others what they thought, and whether it was working. Reminiscent of Schultz's reflection that hubris had been his own flaw and contributed to Starbuck's decline, a former J.C. Penney described Johnson's fatal trait similarly: "His hubris finally did him in" (Clifford, 2013).

Another commentator reports that Johnson's key error at J.C. Penney was not relocating to Texas headquarters; under Johnson, J.C. Penney's leadership team was in fact telecommuting. That is one trait not learned from Jobs who, like leaders at Google and Yahoo, wanted everyone to be at and work from the office since face-to-face interaction fosters innovation, cultural change, and collaboration (Sawyer, 2013). 
Johnson describes his approach to leading J.C. Penney this way: "When I thought about what I could do I wanted to do something that had scale ... I want to do what I did at Apple - I want the chance to transform something. So I picked J.C. Penney. I didn't come here to improve Penney. I'm here to transform Penney." But in self-describing his mistakes at J.C. Penney, limits to intent to transform for transformation's sake emerge. Johnson reported five leadership lessons in an interview after he was fired from J.C. Penney: a company that is not a start-up cannot act like a start-up, not every good decision can be made on intuition, approaches that work at Apple do not work everywhere, being a CEO requires different leadership skills than managing a team, and a legacy business cannot be transformed quickly (Sacks, n.d.).

\section{Larry Page, Co-Founder and CEO of Google}

Being inspired to lead by an iconic leader doesn't necessarily predict failure. Google co-founder Larry Page, like Ron Johnson, found Steve Jobs a leader to emulate (Lashinsky, 2009). Page led Google from its 1998 start until 2001 when he ceded the CEO title to a seasoned professional manager, Eric Schmidt, with whom he and co-founder Sergey Brin then shared management responsibility. In 2011, by then in his late 30's, Page resumed the CEO role at Google (Miller and Helft, 2011).

Not unlike Jobs, Page is described as "aloof, cerebral, intensely private and occasionally brusque" (Miller and Helft, 2011), "a reserved person who thrives on intellectual challenges ... (and who has an) insatiable demand for quick decisions and innovative ideas." Page explains his motivation in reclaiming the CEO role as wanting to bring back the agility and pace his company had at its start, that is, to retain its prominence "as an engine of innovation" (Miller, 2011a).

Though Page is still said to be shy and an avoider of public appearances, he is reported to have sharpened his acumen for internal politics and the presence external interaction calls for. His passion for conceiving and delivering products is said to remain (Miller, 2011a). He seems to couple that now, though, with an impatience to turn things around in his highly competitive industry. Similarly he is said to now keep meetings short, frown upon overuse of email, pay attention to detail while also encouraging big thinking, and make decisions by himself if necessary. He is also described as exhibiting "newfound warmth" (Miller, 2011c). The result? Page's "laser-like focus" along with his "decisiveness and leadership" is reported to have brought clarity to Google, reignited its entrepreneurial nature, and enhanced its core product base (Dumenco, 2011).

\section{Marissa Mayer, CEO of Yahoo}

Marissa Mayer was employee \#20 hired by a young Google, and its first woman engineer. Her technological and quantitative skill combined with a strong work ethic and background as debater and cheerleader to help her at Google create well-designed products wanted by both customers and marketers. As such, she is reported to have "fit in well at Google, where everything depends on how smart you are" ... (and wanting) "to be in the room where the decisions are made" (Guynn and Chang, 2012).

Mayer was often Google's "public face," "a celebrity of sorts in high-tech," and a frequent conference speaker. But when Page resumed Google's CEO title in 2011, Mayer was not among his senior team. Subsequently, she accepted the CEO role at Yahoo, where she became its fifth CEO in five years. Mayer has been described as a perfectionist who is impatient with those "who can't keep up with her," and a fixture in "elite social circles." But she sees herself as a "geek" who is "really impassioned "about her field of technology, and someone who likes to "push myself ... to do something I feel I am not ready to do" (Guynn and Chang, 2012).

At Yahoo, "getting the right talent in the door" appears to be one of Mayer's priorities. She is reported to have quickly become involved in personnel selection, reviewing each and every hire. In doing so, she is said to focus on which university a candidate attended and a candidate's academic credentials (McGregor, 2013). That attention to detail is said to carry over from the focus Mayer gave even to color shades in designing new products at Google (Efrati and Letzing, 2012). 
In 2013, Mayer ended telecommuting at Yahoo explaining that face-to-face interaction furthers collaboration, and that sharing physical space furthers innovation. She appears to be trying to re-spark a declining Yahoo with leadership approaches she learned at Google. As analyst Colin Gillis explains it: "Marissa's trying to increase the energy and output and change the culture of the company ... She brings all the Google lessons to the table, and Google is very focused on having your life revolve around their campus so you can spend a significantly larger chunk of time at work" (Miller and Rampell, 2013).

Time included Mayer in its 2013 roster of the 100 most influential people in the world. It labeled her a "pioneer"x.

\section{Carol Bartz, Former CEO of Yahoo}

Carol Bartz was one who preceded Marisa Mayer as CEO of Yahoo. Wall Street initially applauded Bartz' 2009 selection as CEO by Yahoo, seeing her "as a tough-talking savior who could whip the company into shape" (Kopytoff and Miller, 2011). Bartz' first appearances showed a Yahoo CEO who was decisive and in command. Those who had worked with her previously on corporate boards over the years say that, as a corporate board member, Bartz had earned the respect of executives through her direct and probing questions, realism and insight, and ability to challenge management thinking. That mixture of "candor and toughness" were among the attributes Bartz then brought to Yahoo (Helft, 2009).

In a 2009 reflective interview, Bartz voluntarily identifies a "bad habit" of hers. She reports interrupting and completing another's thought, feeling she knows what that thought is. Bartz explains: "So I actually had to be trained to take a breath. I really want to listen. I want to engage, but I have to shut up. You can see I'm a talker" (Bryant, 2009b).

When asked how her leadership style has changed over time, Bartz says that with confidence she has become calmer. She describes using humor in her style, being good at asking questions, and being driven by "fear of being poor." Moreover Bartz says, "I would hate to describe the CEO I was in '92. I think I was pretty pathetic, actually...I wouldn't have liked working for myself back then" (Bryant, 2009b).

Bartz also discloses feeling the CEO role to be a tremendous responsibility taking a lot of energy as one tries to do it all and often lacks confidence to follow one's instincts. But in 2009 Bartz came out of retirement, where she says she felt bored and missed interacting with people, to lead Yahoo. She depicts herself as loving organizational politics since it charts the way to help people get along and get things done. Additionally, Bartz describes herself as an introvert who needs to be alone to re-center and re-energize (Bryant, 2009b).

Having accepted the CEO position motivated to revitalize Yahoo, Bartz instead experienced "a rocky two-year tenure." When fired in 2011, Bartz' "outspoken style" appeared unchanged. She notified employees in a direct email sent from her iPad that she had been fired by phone by Yahoo's Chairman of the Board (Kopytoff and Miller, 2011).

\section{Mark Zuckerberg, Founder and CEO of Facebook}

Facebook Founder and CEO Mark Zuckerberg, then 26 years old, was named Time's 2010 Person of the Year ${ }^{x i}$. Zuckerberg's vision for what social networking through Facebook could and should be is said to combine with his belief that he can solve any problem, and is reported to manifest in his retaining control and being in charge at Facebook. As early investor Paul Madera explains it, "He always knew before the rest of us what Facebook could be Mark's vision on the purity of the product really did benefit from his control and ownership. It wasn't subject to committee decisions. It was all Mark" (Sengupta, 2012). The vision? In Zuckerberg's words: "I'm trying to make the world a more open place." As social media researcher Danah Boyd explains it: "This is a philosophical battle. Zuckerberg thinks the world would be a better place - and more honest ... If people were more open and transparent" (Vargas, 2010).

Though his stated objective is global transparency, Zuckerberg is described as an unpretentious "brilliant individual" who is also a "wary and private person" that dislikes public appearances. In person, though, he has been known to be 
charming, energetic, thoughtful, reflective, self-deprecating, and relaxed. His office space appears to parallel this. There are no partitions, his desk is in the middle, desks of senior executives are nearby, and conference rooms are small and glassed and named for music bands (Vargas, 2010).

Zuckerberg also does not seem to prioritize making money. While still in his 20's he turned down a billion dollar offer from Yahoo to buy Facebook. Former Yahoo CEO Terry Semel recalls Zuckerberg saying, "It's not about the price. This is my baby, and I want to keep running it, I want to keep growing it." Zuckerberg is said to be fully involved in all new Facebook products and features; he is said to spend afternoons with engineers working on those, to be an intense listener, and to be among the last to leave the office (Vargas, 2010).

Many of the company's early employees have since moved on from Facebook. They describe it to be difficult to work for a friend, and that "Ultimately, it's the Mark show" (Vargas, 2010). But Zuckerberg also is said to seek out the brightest people he can find to advise him (Sengupta, 2012) though he is said to be highly confident. The outcome? In 2010, the same year in which he was selected as Time's Person of the Year, Vanity Fair ranked Zuckerberg No. 1 among the "New Establishment"- just ahead of Steve Jobs (Vargas, 2010).

\section{Sheryl Sandberg, COO of Facebook}

One of those whose desk is in Facebook's open workspace near her 15-year younger boss, Mark Zuckerberg, is Facebook COO and former Google executive Sheryl Sandberg. Sandberg has been credited with turning Facebook into a "real business." In a candid 2013 interview with Oprah Winfrey, Sandberg discloses she was a Facebook user before joining the company, "thought it had amazing power to change the world," and shares Zuckerberg's vision "to connect the whole world." Sandberg also states that her reaction to being on Forbes' 2011 "World's Most Powerful Women" list was embarrassment, and that she responded to congratulations by diverting people from talking about it. Her best-selling 2013 book Lean In helps explain this. There Sandberg reports that as women become more successful they are seen as less likable. She says that results in a tendency for women leaders to not call attention to their accomplishments, and to need to be "relentlessly pleasant" (Oprah Talks to Sheryl Sandberg, 2013).

Some traits of Sandberg and Zuckerberg appear to be mirror opposites. Zuckerberg is said to be an introverted "product visionary" and engineer. Sandberg, though, is described as an extroverted, talkative marketer with strong interpersonal skills who is empathetic and comfortable in the spotlight (Helft, 2010).

Sandberg appears to be one of those smartest people you can find that Zuckerberg is said to gravitate toward. While he dropped out of Harvard as a sophomore to build Facebook, she earned Harvard Bachelor and M.B.A. degrees. Sandberg is credited with "building the largest, most successful advertising building on the Internet" at Google, and helped found its philanthropic effort. She appears to continue those foci at Facebook (Helft, 2010).

At Facebook Sandberg and Zuckerberg appear to have formed a partnership, at Zuckerberg's initiative, in which the pronounced traits of each appear to compliment those of the other. Zuckerberg describes the rationale this way: "A lot of people choose to hire people who look exactly like them. Here we just value balance a lot more (Helft, 2010)."

Sandberg is reported to be multi-dimensional and highly functional. Both a strategic thinker and facilitator of productive teamwork, she is described as having entered Facebook's techie headquarters somewhat out of place in the elegant attire she and her corporate background tend toward. Her approach? On her first day at Facebook Sandberg went to each desk of existing staffers, introduced herself, told jokes, and asked questions. She has since become know for mentoring many of Facebook's younger workers. The result? Sandberg was apprised as legitimate and has been accepted at Facebook, and then some (Helft, 2010). In 2012, she was described as "a not-so-secret weapon for recruiting and retaining talented women as well as men... Sheryl is radioactive plutonium when it comes to a recruiting weapon." More than 200 Google employees have followed Sandberg to Facebook (Perlroth and Miller, 2012).

For years Sandberg has built and maintained a networking group of Silicon Valley women, for whom she hosts monthly dinner parties at her home at which highly prominent figures speak. She is reported to have become a role 
model for many inside and outside the industry, and to have achieved near celebrity status to them. Encouraging women to lead has become synonymous with Sandberg. Though she is not alone in having achieved top ranks as a woman in the technology sector, it is said that "none have made promoting women a cause the way Ms. Sandberg has." Many of her public talks and her commencement addresses have gone viral, and some are required viewing in top business schools (Perlroth and Miler, 2012).

Time included Sandberg in its 2013 roster of the 100 most influential people in the world. It labeled her a "titan"xii .

\section{Robert Iger, Chairman and CEO of The Walt Disney Company}

Robert Iger leads the world's largest media company, The Walt Disney Company. Iger began his career with now Disney-owned ABC in 1974, and progressed through the company becoming Disney's President and COO in 2000, and its President and CEO in 2005. The Walt Disney Company website reports Iger as named by Fortune as one of the"25 Most Powerful People in Business" for 2006 and 2007; by Forbes as one of 2009's "Top Gun CEOs"; by Institutional Investor as one of the "Best CEOs" for 2008, 2009, 2010, and 2011; and by MarketWatch as 2006 CEO of the Year ${ }^{\text {xiii }}$. Iger was recommended by his predecessor Michael Eisner to succeed him when Eisner left Disney. Concerned that he might be perceived as a "yes man," Iger determined to "exceed expectations" instead (Siklos, 2009). Perhaps that was sparked by Iger having been told by his first ABC boss that he was not promotable (Barnes, 2010).

The attributes that have enabled Iger to exceed expectations as CEO are widely reported. He is described as combining willingness and ability to take large, strategic chances with a preference for keeping a low public profile and "managing inside the walls." $\mathrm{He}$ is said to mix competitive nature, strong work ethic, and intense focus on quality and its measurement with an unpretentious easy manner, good nature, and sense of humor. Iger's character and diplomatic skill are reported to have enabled him to mend torn relationships with those as pivotal to the company as Steve Jobs, from whom the company was then able to purchase Pixar, and founder-descendent Roy Disney. Steve Jobs said of Iger: "I consider Bob Iger a friend. I don't have a lot of friends. I just really like him, and he's a really solid guy" (Siklos, 2009).

Iger's Disney is reported to be "faster moving and more aggressive" in its initiatives under his lead. At the same time, the highly energetic Iger is reported to lead by consensus, empower his team, and let others take the credit rather than be spotlighted himself. Iger credits ABC CapCities mentor Thomas Murphy with having taught him to put great people in place, let them deliver, get involved responsibly, but not undermine their authority. Consistent with this the meetings Iger runs are described as conversations, he has installed a door to his office on a busier hallway, and he routinely gets out to brainstorm with line workers (Grover, 2007).

Iger self-describes as believing in himself enough to know if he's not good at something, and if he's not good at something to get good at it or to try something else. Iger also says he loves "being curious" about the world, the business, new business models, and new technology. He describes leadership as done by example, with directness, with presence, with listening, with focus, and with patience (Bryant, 2009a).

The result? Iger has amassed dedicated supporters. Berkshire Hathaway Chairman and CEO Warren Buffett explains it this way: "He's not constantly trying to show you how smart he is, and that is a very important trait in Hollywood, where you've got to rely on talent who consider themselves to be the center of the universe. Bob is the type of guy you want to help. When he calls I don't spend time thinking, “'How do I tell this guy no?' It's 'How do I tell this guy yes?' And I don't feel that way about many people” (Barnes, 2010).

Perhaps that, unlike Johnson at J.C. Penney, reflects Iger's ability to balance Disney's long tradition with enthusiasm for changes his industry is experiencing. Citing Churchill as having successfully balanced heritage with innovation, Iger says: "Our brand is so powerful because of our heritage. But you've got to innovate, and not just in terms of what is new today but what will be new far into the future (Barnes, 2010)." Stopping to saying hello to an employee working in the building one day, Iger was heard telling her "It's the happiest place on earth ... Let's keep it that way (Siklos, 2009)." 


\section{Jeff Bezos - Founder and CEO of Amazon.com}

Jeff Bezos is a Princeton-trained computer scientist and electrical engineer who 20 years ago left a Wall Street financial analyst job to found the company Amazon.com that he envisioned in commercial Internet's early days. Time named Bezos 1999's Man of the Year, and Investor's Business Daily chose him 2009's CEO of the Year. Wharton professor Kartik Hosanagar describes Bezos' footprint this way: "He's constantly reinventing Amazon.com. Most successful companies are too afraid to touch the status quo and experiment with something that's working." But not so Bezos. Rather, "he has created a culture of constant innovation at Amazon.com." That innovation appears to result from a combination of intuition and data-driven decision-making. Bezos is reported to have and welcome ideas but to test them with customers for profitability. He also is said to combine a strong sense of humor and a signature laugh with "cold-blooded businessman" affect (Seitz, 2010).

In 2012, after Steve Jobs' 2011 death, Forbes called Jeff Bezos America's No. 1 CEO. It described Bezos as "equal parts quant and dreamer" ... who "still dashes around Amazon with the intensity of a startup boss trying to make his first payroll, as well as the glee of a teenager discovering all the fun you can have at overnight camp." At meetings, Bezos tends to leave an open seat at the table and say that the occupant of that "empty chair" is the customer, who is the most important attendee there and who is to be considered in all decisions. Bezos is reported to read unsolicited over-the-transom emails, and to often operationalize suggestions they contain. Bezos describes the nature and operationalization of his customer-first commitment this way: "We don't focus on the optics of the next quarter; we focus on what is going to be good for customers. I think this aspect of our culture is rare" (Jeff Bezos Reveals His Number 1 Leadership Secret, 2012).

Bezos' leadership attributes have led to comparison to Steve Jobs; both are heralded by some as visionaries, and both have been said by some to be horrid to work for. Both are reported as being sharply focused, and capable of expressing cutting remarks toward employees whom they see as off-track (Sorenson, 2013). Bezos' employees have labeled such episodes, in which his blood vessels would start to throb before he started a tirade, "nutters (Squeo, 2013)."

Some explain that such leaders are "gladiators" who made their own rules as there weren't any rules in place as these combatants chartered new paths (Squeo, 2013). Others describe such leaders as ones to whom the right course is clear and integral to them, whereas that path might not be as evident or vital to someone else. Regardless, these out-sized leaders appear to produce an intense motivation that unleashes more and better work from employees. In Bezos' case, his vision generated successes early on and has justified his approach ever since. The result? Staying power. Amazon.com's top ten executives have stayed with the company on average ten years (Anderson, 2013).

\section{THE IN-FACTOR}

Comprehensive review of academic and practitioner literature encompassing both primary and secondary sources, then, reveals both a robust and complex portrait of contemporary leaders of innovation. They vary in age, gender, industry, education, training, experience, and socioeconomic background. They neither travel identical paths, nor do they have identical behavioral styles. Some founded the companies they still lead, others founded those companies having worked elsewhere previously, others succeeded those who founded the company, and others succeeded other non-founders; some lead singularly, and some partner; some maintain tight control, and others empower; some are introverts, and some are extroverts; some are more narcissistic, and some are more empathetic; some focus on conceiving breakthrough products or services, and some focus on breaking through macro and micro operational challenges .

What emerges, though, is an array of signature traits that these "Imagineers" tend to share. Successful leaders of innovation appear to combine the right brain propensity to imagine with the left brain propensity to reason. They are reflective and experiential learners, comfortable with and progressing from the mistakes which they consider are an inevitable part of innovation and growth. They are passionate about the vision they aspire toward, and are deeply vested in its attainment. They are focused about, fueled by, and immersed in the work they do. They tend to work more than they sleep, and work at keeping themselves tuned up. They are curious about and are in touch with themselves, their industry, and their times. They are cognitively, emotionally, and politically smart, and are 
authenticity and visibly present. They have an internal locus of control, and evidence character. They navigate equilibrium between heritage and innovation. They are ready and want to lead, and trigger a desire in others to follow their lead. They want to make an essential difference, and are seen as doing so.

This is a daunting set of characteristics possessed to varying degrees, developing over time, and surfacing more or less as called for by differing situations. It is not intended as a litmus test by which, in comparison to, those seeking to enter the leadership pipeline feel inadequate and needlessly opt out. Rather, synthesizing the findings, there is an overriding innovative attribute that successful leaders of innovation clearly and positively share, whether as mavericks or as those who break through: The IN-Factor, the INtention and INsistence to be a trailblazer. Those who have the IN-factor possess an intensity that is more forceful than drive, a certainty and commitment that is more compelling than dedication, and a failure is not an option gestalt that brings an inevitability to their leadership and energizes followership. Table 2, below, summarizes the IN-Factor's ten signature traits.

Table 2. The IN-Factor - Ten Signature Traits of Innovation's Leaders

\begin{tabular}{ll}
\hline & \multicolumn{1}{c}{ The Intention And Insistence To Be A Trailblazer } \\
\hline 1. & Invested: Passionate about vision and committed to its attainment \\
2. & Integrated: Focused toward, fueled by, and fully engaged in work \\
3. & In touch: Reflective and experiential; curious about and in tune with self, industry, and times \\
4. & Intelligent: Cognitively, emotionally, and politically smart \\
5. & In place: Authentically and visibly present \\
6. & Internal locus of control: Responsible for own performance \\
7. & Integrity: Embodiment of character \\
8. & In sync: Balance between heritage and innovation \\
9. & Ingrained: Leadership ready, willing, and able \\
10. & Indispensible: Determined to make an essential difference and seen as doing so \\
\hline
\end{tabular}

\section{CONCLUSION}

Two quotes by Steve Jobs ${ }^{\text {xiv }}$ articulate the IN-Factor in the words of one who had it:

"My job is not to be easy on people. My job is to take these great people we have and to push them and make them even better."

“Don't be trapped by dogma - which is living with the results of other people's thinking. Don't let the noise of other's opinions drown out your own inner voice. And most important, have the courage to follow your heart and intuition. They somehow already know what you truly want to become. Everything else is secondary."

The literature and examples examined for this study were intentionally selected for currency to optimize usage in current leadership education, development, and training efforts. The study would be incomplete though without clarifying that "Imagineering" is not a fad, and is neither momentary nor insignificant. Had Thomas Edison (18861931) been alive today, for instance, he would have been found to have the IN-Factor. These words, which are his, could have been said by any of the leaders examined for this study: "There's a way to do it better - find it. Moreover, management guru Peter Drucker (1909-2005) described leadership as he studied it in the $20^{\text {th }}$ century in words equally confirming the enduring nature of these signature traits:

"Leadership is lifting a person's vision to high sights, the raising of a person's performance to a higher standard, the building of a personality beyond its normal limitations. ${ }^{\text {xvi, }}$ - Peter Drucker

\section{AUTHOR BIOGRAPHY}

Susan Eisner is a Professor of Management at Ramapo College's Anisfield School of Business. Before teaching she held leadership positions in television, health care/foundation, and national politics. Her graduate degree is from Harvard's Kennedy School, where she was an Administration Fellow. Her research/teaching includes leadership, organizational behavior, interpersonal skills, diversity, creativity, and entertainment/media management. She has 
received the College's Thomases Award for Faculty Excellence, and the School's Outstanding Teacher Award. Her biographical recognitions include Who's Who in the World, Who's Who in America, and Who's Who Among America's Teachers. She is a Director of the Society for Advancement of Management.

\section{DEDICATION}

This paper is dedicated to my parents, Nathaniel Julius Eisner (1920-2014) and Frances Rochelle Linick Eisner (1922-), both first generation Americans. For more than 90 years each exemplified and advanced the IN-Factor.

\section{REFERENCES}

Air Herb's secret weapon. (1999, July/August). Chief Executive Magazine, 146, 32-42.

Alvarez, J.L., Svejenova, S, \& Vives, L. (2007, Summer). Leading in pairs. MIT Sloan Management Review, 48 (4), $10-14$.

Amabile, T. (1996, January 5). Creativity and innovation in organizations. Background Note. Harvard Business Publishing, Product 396239-PDF-ENG.

Amabile, T., \& Khaire, M. (2008, October 1). Creativity and the role of the leader. Harvard Business Review, Product R0810G.

Anderson, G. (2013, October 22). Is Jeff Bezos a horrible boss and is that good? Forbes.

Barnes, B. (2010, April 9). Is Disney's chief having a Cinderella moment? The New York Times.

Barrett, C. (2011, October). Servant leadership. Leadership Excellence, 28 (10), 4-5.

Battley, S. (2012, December 13). The 2012 CEO all-stars and dimmed stars. Forbes.

Bell, C., \& Patterson, J. (2013, July). Great leaders. Leadership Excellence, 30 (7).

Bennis, W., \& Thomas, R. (2002, September 1). Crucibles of leadership. Harvard Business Review, Product R0209B.

Bryant, A. (2009a, May 3). Corner Office: He was promotable, after all. The New York Times.

Bryant, A. (2009b, October 18). Corner Office: Imagining a world of no annual reviews. The New York Times.

Bryant, A. (2010, October 9). Good CEO's are insecure (and know it). The New York Times.

Bryant, A. (2011, April 16). Distilling the wisdom of CEOs. The New York Times.

Chmielewski, D., \& Guynn, J. (2009, January 16). Leadership: Cook relies on core values as Jobs' surrogate at Apple. Los Angeles Times.

Clifford, S. (2013, April 9). Chief's Silicon Valley stardom quickly clashed at J.C. Penney. The New York Times.

Dubrin, A. (2013). Leadership: Research findings, practice, and skills ( $7^{\text {th }}$ ed.). Mason, OH: South-Western, Cengage Learning.

Dumenco, S. (2011, September 26). Is Google's Larry Page already turning out to be a truly great CEO? Advertising Age, 82 (34).

Efrati, A., \& Letzing, J. (2012, July 18). Yahoo goes back to roots with pick. Wall Street Journal, Europe.

Finkle, T., \& Mallin, M. (2010). Steve Jobs and Apple, Inc. The International Academy for Case Studies, 16 (7), 31-40.

Goleman, D. (2004, January 1). What makes a leader? Harvard Business Review, Product R0104H.

Goleman, D. (2013, December 1). The focused leader. Harvard Business Review, Product R1312B.

Grover, R. (2007, February 5). How Bob Iger unchained Disney. Business Week.

Guynn, J., \& Chang, A. (2012, July 18). Exec and expectant mother blazes trail to top Yahoo job. Los Angeles Times.

Helft, M. (2009, January 17). No time for Yahoo 'nonsense;' new CEO's manner impresses employees. International Herald Tribune.

Helft, M. (2010, October 2). Mark Zuckerberg's most valuable friend. The New York Times.

Holstein, W. (April 1, 2007). What consultants may not know about leadership. The New York Times.

Isaacson, W. (2012, April). The real leadership lessons of Steve Jobs. Harvard Business Review. Retrieved from http://hbr.org.

Jeff Bezos reveals his no. 1 leadership secret. (2012, April 4). Forbes.

Kahney, L. (2008, March 18). How Apple got everything right by doing everything wrong. Wired Magazine.

Kopytoff, V., \& Miller, C. (2011, September 6). Yahoo board fires chief executive. The New York Times.

Kopytoff, V., \& Streitfeld, D. (2011, August 25). Big shoes at Apple, but maybe not unfillable. The New York Times.

Kramer, R. (2006, February 1). Great intimidators. Harvard Business Review, Product R0602D.

Lashinsky, A. (2009, November 5). The decade of Steve: How Apple's imperious, brilliant CEO transformed American business. Fortune.

Lohr, S. (2011, August 25). Without its master of design, Apple will face many challenges. The New York Times.

Maccoby, M. (2004, January 1). Narcissistic leaders: The incredible pros, the inevitable cons. Harvard Business Review, Product R0401J.

McGregor, J. (2013, March 12). Marissa Mayer's un-or-tho-dox leadership at Yahoo. The Washington Post.

Menkes, J. (2011, May 11). Learning how to realize potential: How great leaders tap into the innately human need to achieve. Harvard Business Press Chapters, Product 8544BC.

Miller, C. (2011b, March 12). A changed Starbucks: A changed CEO. The New York Times.

Miller, C. (2011a, January 21). A creator prepares to take the reins at Google. The New York Times.

Miller, C. (2011c, November 9). Google's chief works to trim a bloated ship. The New York Times. 
Miller, C. \& Helft, M. (2011, January 20). Google shake-up is effort to revive start-up spark. The New York Times. Miller, C., \& Rampell, C. (2013, February 25). Yahoo orders home workers back to the office. The New York Times. O’Brien, C. (2012, December 8). Technology: Apple's CEO steps out of Steve Jobs' shadow. Los Angeles Times. Oprah talks to Sheryl Sandberg. (2013, April). O: The Oprah Magazine.

Perlroth, N., \& Miller, C. (2012, February 4). The \$1.6 billion woman, staying on message. The New York Times.

Sacks, D. (n.d.). Leadership: Ron Johnson's 5 key mistakes at JC Penney, in his own words. Fast Company. Retrieved from http://www. fastcompany.com/3008059/ron-johnsons-5-key-mistakes.

Sawyer, K. (2013, April 10). MarketWatch: Why Ron Johnson's Apple magic failed J.C. Penney. The Wall Street Journal.

Sengupta, S. (2012, February 2). Zuckerberg remains the undisputed boss at Facebook. The New York Times.

Seitz, P. (2010, January 4). Amazon.com whiz Jeff Bezos keeps kindling hot concepts. CEO of the year: He carried the retailer up from the dot-bomb rubble. Investor's Daily Business.

Siklos, R. (2009, January 19). Bob Iger rocks Disney. Fortune, 159 (1), 80-86.

Sorensen, C. (2013, November 18). Really bad bosses. Maclean's.

Spreier, S., Fontaine, M., \& Malloy, R. (2006, June 1). Leaders run amok: The destructive

potential of overachievers. Harvard Business Review, Product R0606D.

Squeo, A. (2013, October 13). Like it or not, gladiator CEOs like Bezos fuel society's advancement. Forbes.

Strout, E. (2002, April). Crafty or crazy? Sales and Marketing Management, 154 (4), 28-33.

Vargas, J. (2010, September 20). The face of Facebook. The New Yorker.

Weisman, R. (200, March 26). Need to shake things up? A bullying boss may be best. Boston Globe.

Whitworth, D. (2011, March 12). I worry about everybody. I'm paranoid: You have to be. The Times (London).

\section{ENDNOTES}

i At http://www.merriam-webster.com/dictionary/innovation

ii Generation Y/Millennials, are those born between 1997 and the start of the $21^{\text {st }}$ century (some end Generation Y at 1995 , some at 2001).

iii Citations from J2Global Survey and Kauffman Foundation reports as cited in http://www.huffingtonpost.com/martyzwilling/tips-for-gen-y-on-how-to_b_3958917.html.

${ }^{\text {iv }}$ Citations from Employers Insurance and Millennial Branding/oDesk as reported in Schawbel, D. (2013, June 25). "74 of the most interesting facts about the millennial generation." At http://danschawbel.com/blog/74-of-the-most-interesting-facts-aboutthe-millennial-generation/.

' 1: Reflections on leadership. (2011, Autumn). SAM Advanced Management Journal, 76(4), 47-61. 2: Leadership and gender. (2013, Winter). SAM Advanced Management Journal, 78 (1), 26-41.

${ }^{v i}$ Dubrin, A. (2013). Leadership: Research findings, practice, and skills $\left(7^{\text {th }}\right.$ ed.). Mason, OH: South-Western, Cengage Learning.

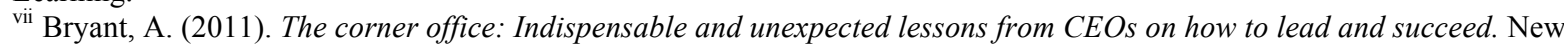
York, NY: Times Books.

viii At http://money.cnn.com/galleries/2012/news/companies/1203/gallery.greatest-entrepreneurs.fortune/index.html.

${ }^{\text {ix }}$ At http://swamedia.com/channels/Officer-Biographies/pages/herb_kelleher.

${ }^{x}$ At http://time100.time.com/2013/04/18/time-100/slide/all/.

${ }^{x i}$ At http://content.time.com/time/interactive/0,31813,1681791,00.html.

${ }_{\text {xii }}$ At http://time100.time.com/2013/04/18/time-100/slide/all/.

xiii At http://thewaltdisneycompany.com/about-disney/leadership/ceo/robert-iger.

xiv At http://www.forbes.com/sites/ekaterinawalter/2013/09/30/50-heavyweight-leadership-quotes/.

${ }^{x v}$ At http://www.leadershipnow.com/creativityquotes.html.

${ }^{x v i}$ At http://www.forbes.com/sites/kevinkruse/2012/10/16/quotes-on-leadership/. 


\section{NOTES}

